Supporting Information

\title{
Photolithographic patterning of FluorAcryl for biphilic microwell-based digital bioassays and selection of bacteria
}

Arianna Toppi ${ }^{a}$, Louise L. Busk ${ }^{a}$, Hongxia Hur, Asli A. Dogan ${ }^{a}$, Alexander Jönsson ${ }^{a}$, Rafael J.

Taboryski ${ }^{b}$, Martin Dufva ${ }^{a^{*}}$

a. Dept. of Health Technology, Technical University of Denmark, 2800 Kgs. Lyngby,

Denmark.

b. DTU Nanolab, National Centre for Nano Fabrication and Characterization, Technical

University of Denmark, 2800 Kgs. Lyngby, Denmark.

* Corresponding author: Prof. Martin Dufva - E-mail: dufva@dtu.dk 


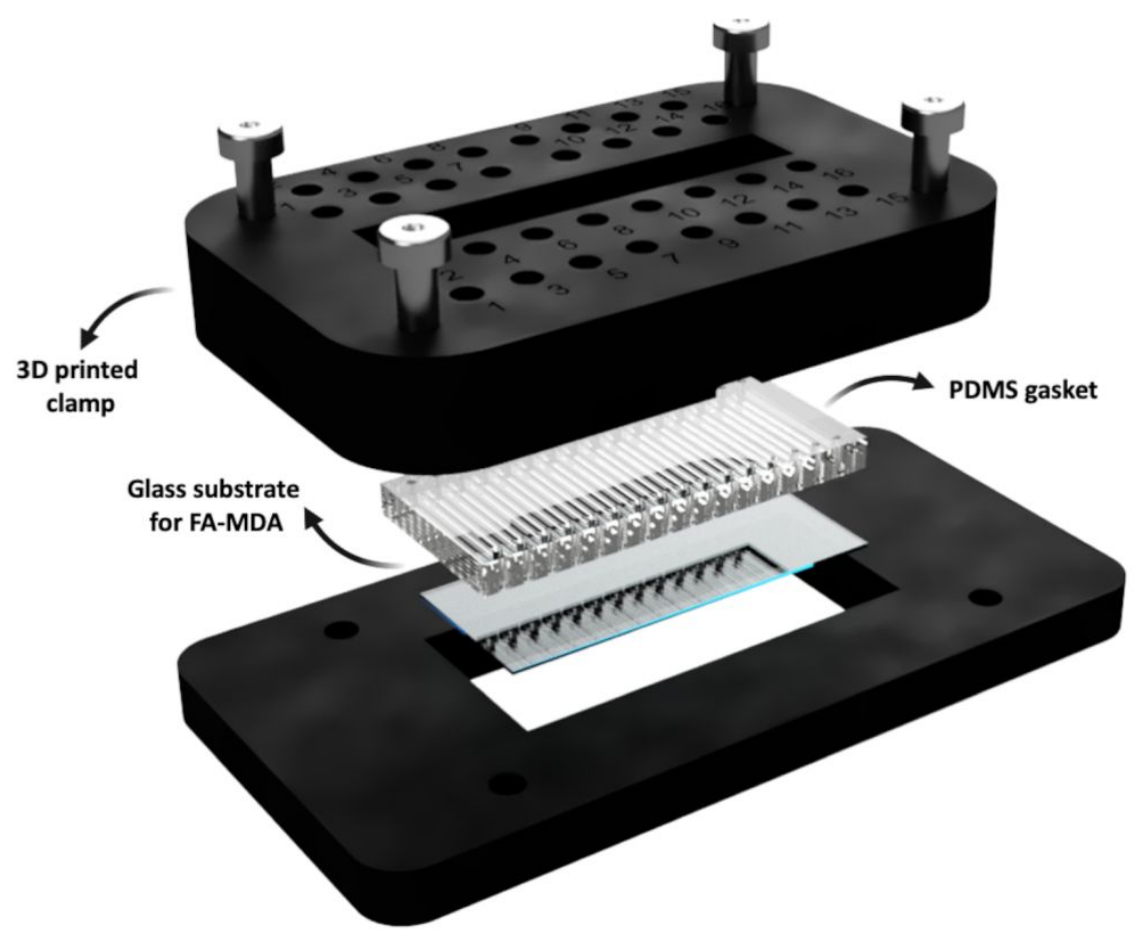

Figure S1 Expanded microfluidic device. A PDMS gasket interfaces with a $19.5 \mathrm{~mm}$ x 45

mm glass chip forming micro-channels when the device is assembled; The clamping system is printed in Formlabs black resin. 

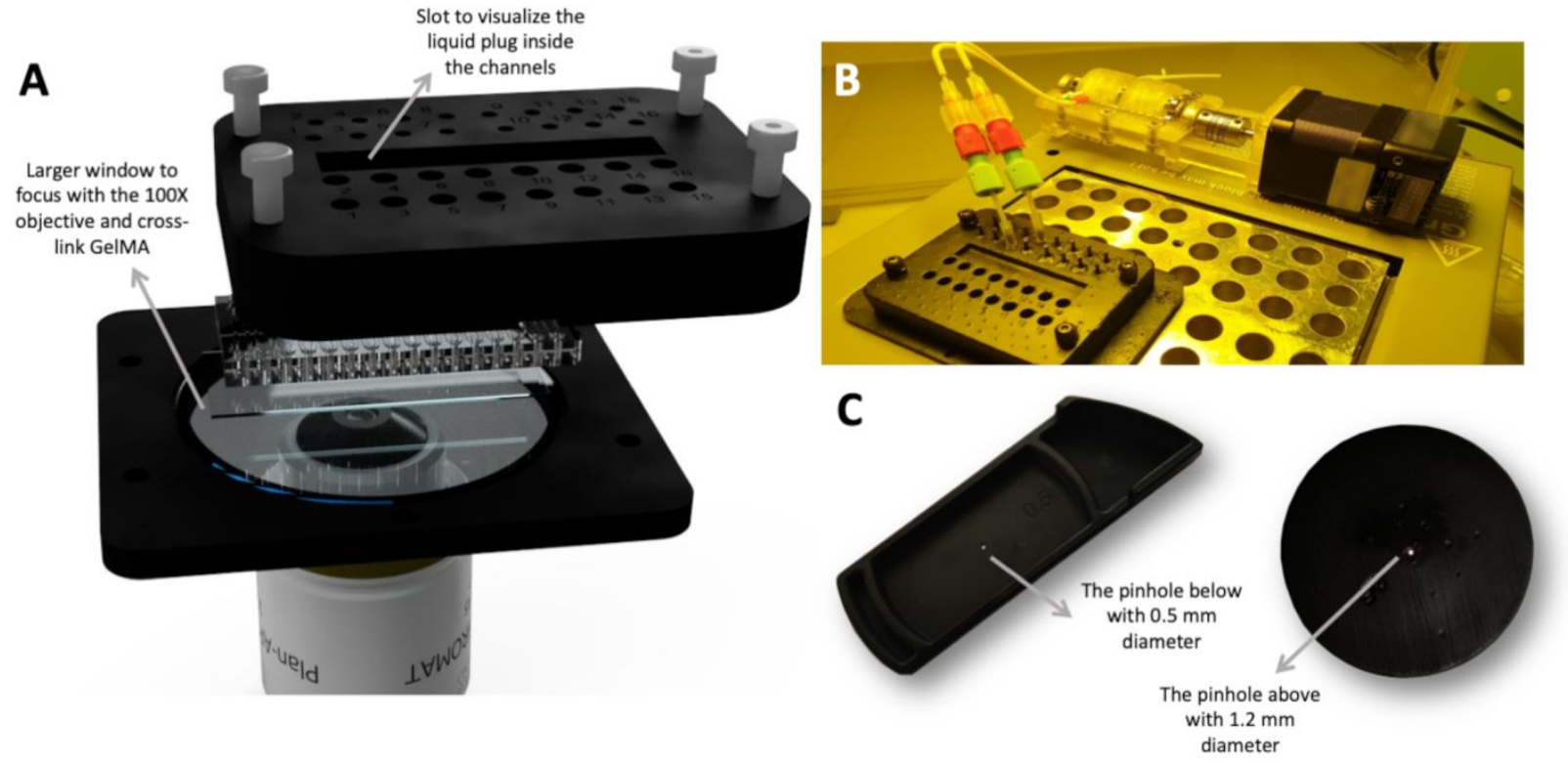

Figure S2 A) Expanded 3D model of the 3D printed fluidic system containing the FluorAcryl

patterned glass slide for bacteria trapping and selection. B) 3D printed fluidic system connected to the $3 \mathrm{D}$ printed peristaltic pump. C) Picture of the $3 \mathrm{D}$ printed pinholes used for photocrosslinking GelMA with the 100X objective (LD EC EpiPlnN 100x/0.75, Zeiss ${ }^{\mathrm{TM}}$, Germany) in the fluorescence microscope (Axio Observer Z1, Zeiss ${ }^{\mathrm{TM}}$, Germany). 

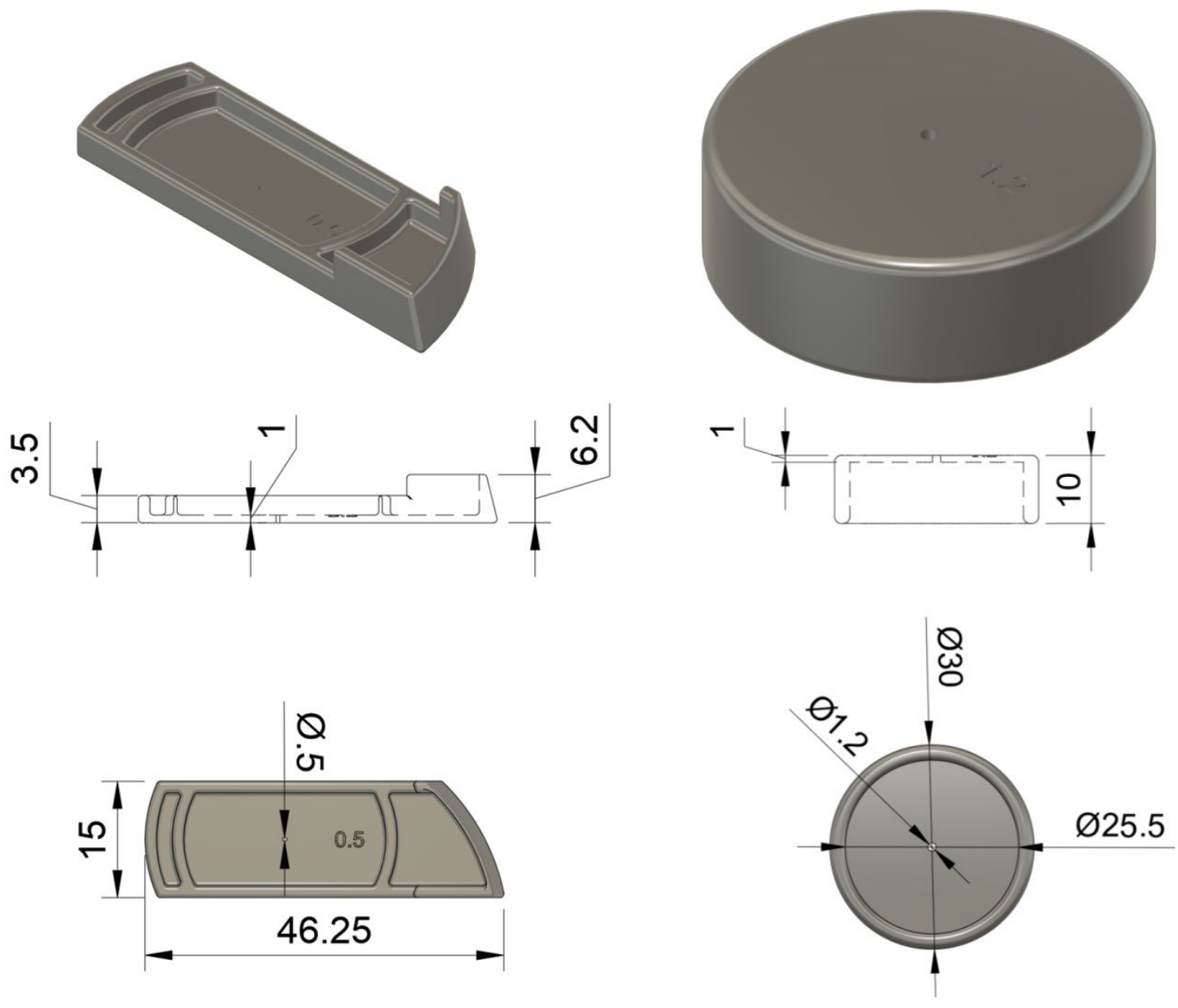

Figure S3 3D models and dimensions of the 3D printed pinholes used to center the exciting light through the 100X objective into a small defined area during GelMA crosslinking. The unit of measurement is $\mathrm{mm}$. 


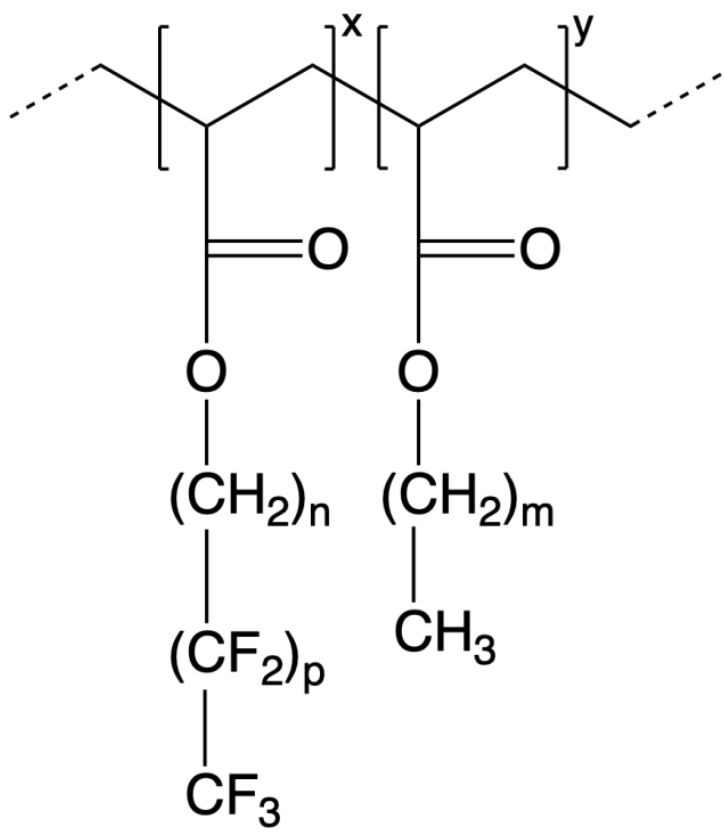

Figure S4 Simplified structure of a fluoroacrylate polymer. Adapted from Heydebreck, F.;

Tang, J.; Xie, Z.; Ebinghaus, R. Emissions of Per- and Polyfluoroalkyl Substances in a Textile Manufacturing Plant in China and Their Relevance for Workers' Exposure. Environ.

Sci. Technol. 2016, 50 (19), 10386-10396. 

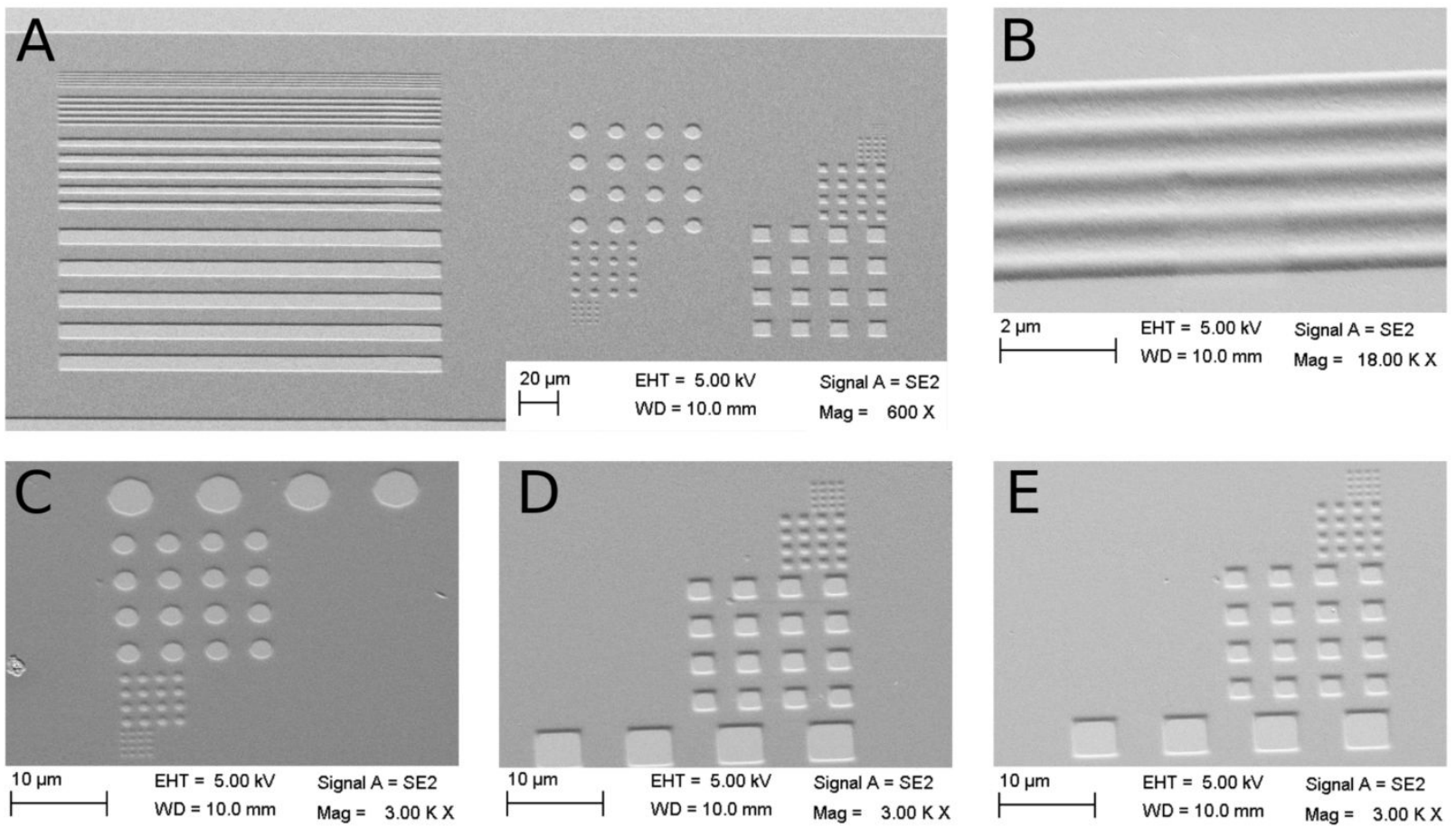

Figure S5 SEM micrographs of the resolution structures at various doses. A) Overview of the resolution structure. The pattern seems well-reproduced except for the smallest $1 \mu \mathrm{m}$ structures. B) magnified view of the $1 \mu \mathrm{m}$ lines reveal how the structures appear blurred because of the gradual dose-response. C) resolution structures at a dose of $140 \mathrm{~mJ} / \mathrm{cm}^{2}$, D) at a dose of 440 $\mathrm{mJ} / \mathrm{cm}^{2}$, and E) at $740 \mathrm{~mJ} / \mathrm{cm}^{2}$, respectively. The sample is coated with a $10 \mathrm{~nm}$ thick layer of gold. 

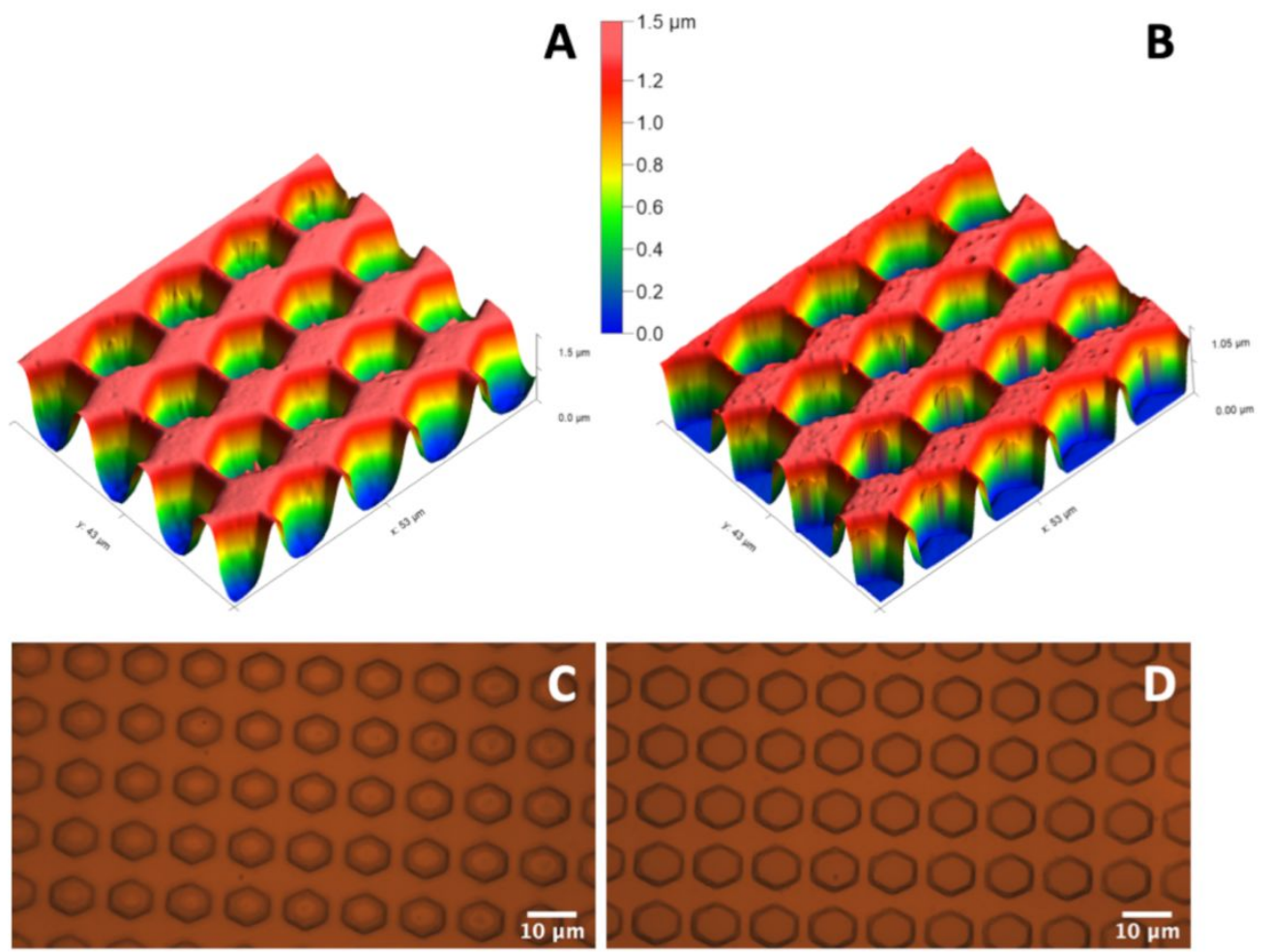

Figure S6 A) 3D topographic image of the well array on FluorAcryl 3298 taken using a Sensofar Optical Profiler before the descum process and B) corresponding 3D topographic image after the descum process. C) Brightfield micrograph of the well array before descum and D) corresponding brightfield micrograph after the descum process. 
The conical shape of the wells in the 3D topographic image is an indication of the presence of resist residuals covering the glass surface in the bottom of the wells before the descum process. This is also clearly visible in the brightfield micrograph, where the area inside the hexagons is not flat. It appears flat after the descum process.

Chemical resistance of $\boldsymbol{U V}$ cured FluorAcryl. The chemical resistance and anti-fouling properties claimed by the manufacturer were tested by exposing cured, patterned FA samples to various chemical environments. Table S1 summarizes the results of the analysis; The first column describes the chemical treatment, the second column states the integrity of the FA film as measured by optical microscopy, and the last column states changes in hydrophobicity, as measured by contacting the surface with a water droplet before and after treatment and comparing the images.

Supplementary Table S1. Results of the chemical resistance test of UV cured FluorAcryl

\begin{tabular}{|c|c|c|}
\hline Treatment & Film integrity & Change in hydrophobicity \\
\hline Oxygen plasma $(10 \mathrm{~min})$ & Intact & Very hydrophilic \\
\hline Microposit $^{\mathrm{TM}}$ Remover $1165(10 \mathrm{~min})$ & Intact & No change \\
\hline
\end{tabular}




\begin{tabular}{|c|c|c|}
\hline Toluene (30 min) & Intact & No change \\
\hline Ethyl/butyl acetate $(36 \mathrm{~h})$ & Intact & No change \\
\hline Acetone $(10 \mathrm{~min})$ & Intact & No change \\
\hline 2-propanol $(10 \mathrm{~min})$ & Intact & No change \\
\hline Ethanol (30 min/10 min + ultrasound $)$ & Intact & No change \\
\hline Sulphuric acid pH. 1.0 (10 min.) & Intact & No change \\
\hline Acetic acid pH 5.0 (10 min) & Intact & No change \\
\hline Sodium bicarbonate pH $10.0(10 \mathrm{~min})$ & Intact & No change \\
\hline Sodium hydroxide $\mathrm{pH} 13.0(10 \mathrm{~min})$ & Intact & No change \\
\hline
\end{tabular}




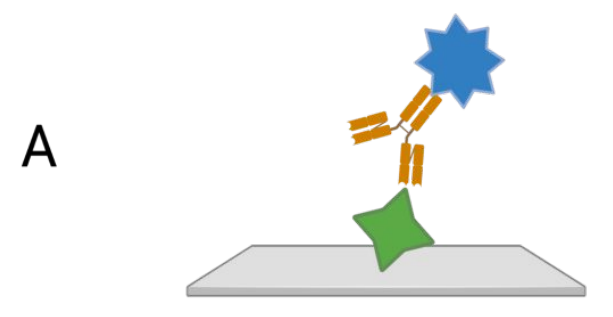

B

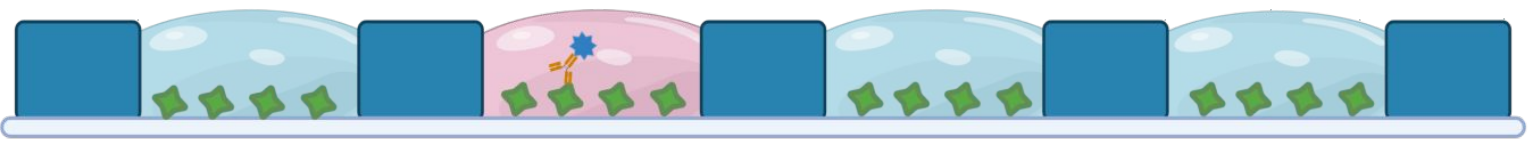

Figure S7 Schematic of the digital ELISA assay on FA-MDAs. A) Tau protein, used as capture probe, was covalently bound to the glass surface in the bottom of the wells previously functionalized with epoxy groups. HRP-conjugated Anti-Tau antibody was used as analyte in extremely low-concentrated samples and detected through the single-molecule counting method, where only one or no analyte molecules were immobilized in each well. B) A fluorescent signal detectable with a common fluorescence microscope was generated inside the wells containing the analyte in the presence of the HRP substrate. Illustration created with BioRender.com. 


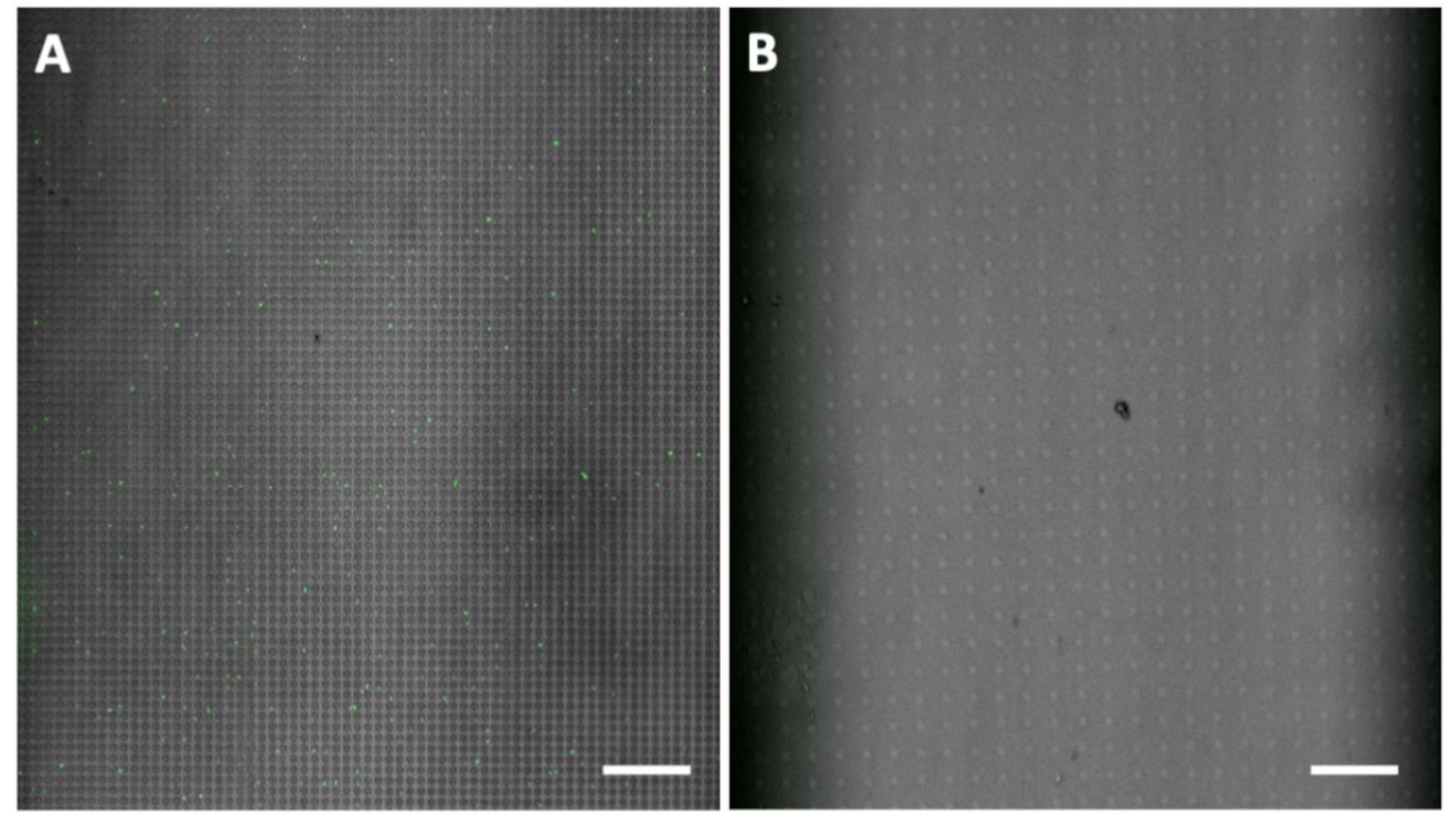

Figure S8 Bacteria trapping. Comparison between a FluorAcryl well array (A) and one of the FDTS coated biphilic surfaces forming a microdroplet array typically used in the group, where the spots have $10 \mu \mathrm{m}$ diameter and $20 \mu \mathrm{m}$ pitch (B) for bacteria trapping. In the first case, bacteria fall and are physically trapped inside the wells while the liquid slowly flushes through the channel. On the biphilic surface, being flat, bacteria cannot be physically trapped and are dragged out of the channel by the liquid plug. Scale bars are $100 \mu \mathrm{m}$. 

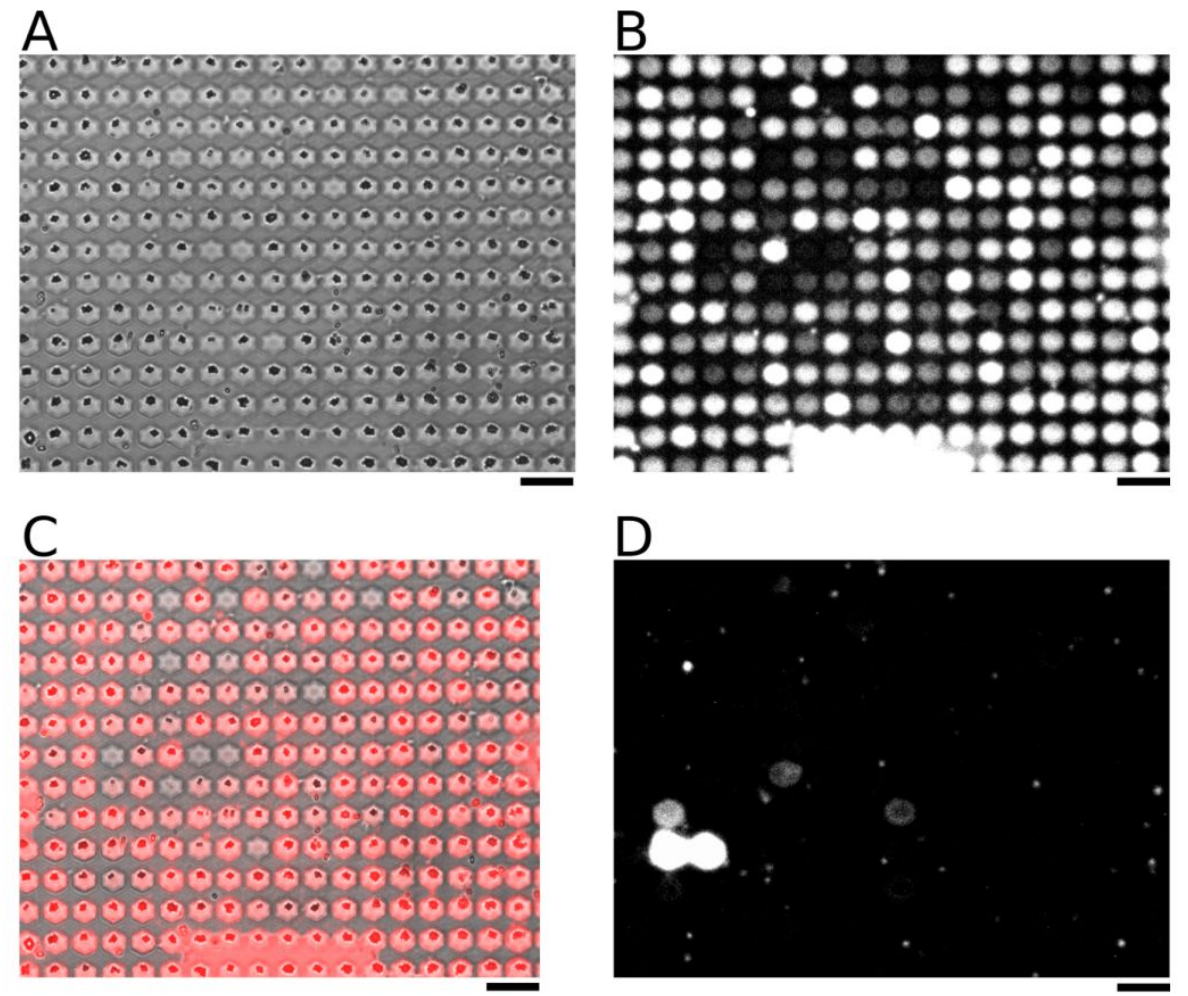

Figure S9 Capture of HRP-functionalized magnetic beads in the FA array. Streptavidincoated beads $(2.8 \mu \mathrm{m}$, Dynabeads, Invitogen) were modified with a biotinylated capture oligonucleotide. The beads were then hybridised in solution with the corresponding oligonucleotide target and subsequently labelled with HRP-conjugated streptavidin. Afterwards, the solution containing the functionalized beads was pumped over a FA-MDA 
and the beads were captured. Finally, the fluorogenic HRP substrate was passed over the FA-MDA and the droplet array was generated. A) Shows the brightfield image of captured beads in the FA-MDA, with one or more beads visible in most but not all the wells. B) Shows the corresponding fluorescence image of the droplets after the enzymatic reaction. C) Shows an overlay of A) and B) with red false color for B). Signals are only generated in wells with beads and hence with the HRP enzyme present. D) Fluorescence micrograph from a negative control sample where no complementary oligonucleotide, and hence HRP, were added. The beads present little autofluorescence but very few droplets give false positive signals. This result demonstrates that bead-based assays are feasible using FA-MDA. Scale bars are 20 $\mu \mathrm{m}$. 


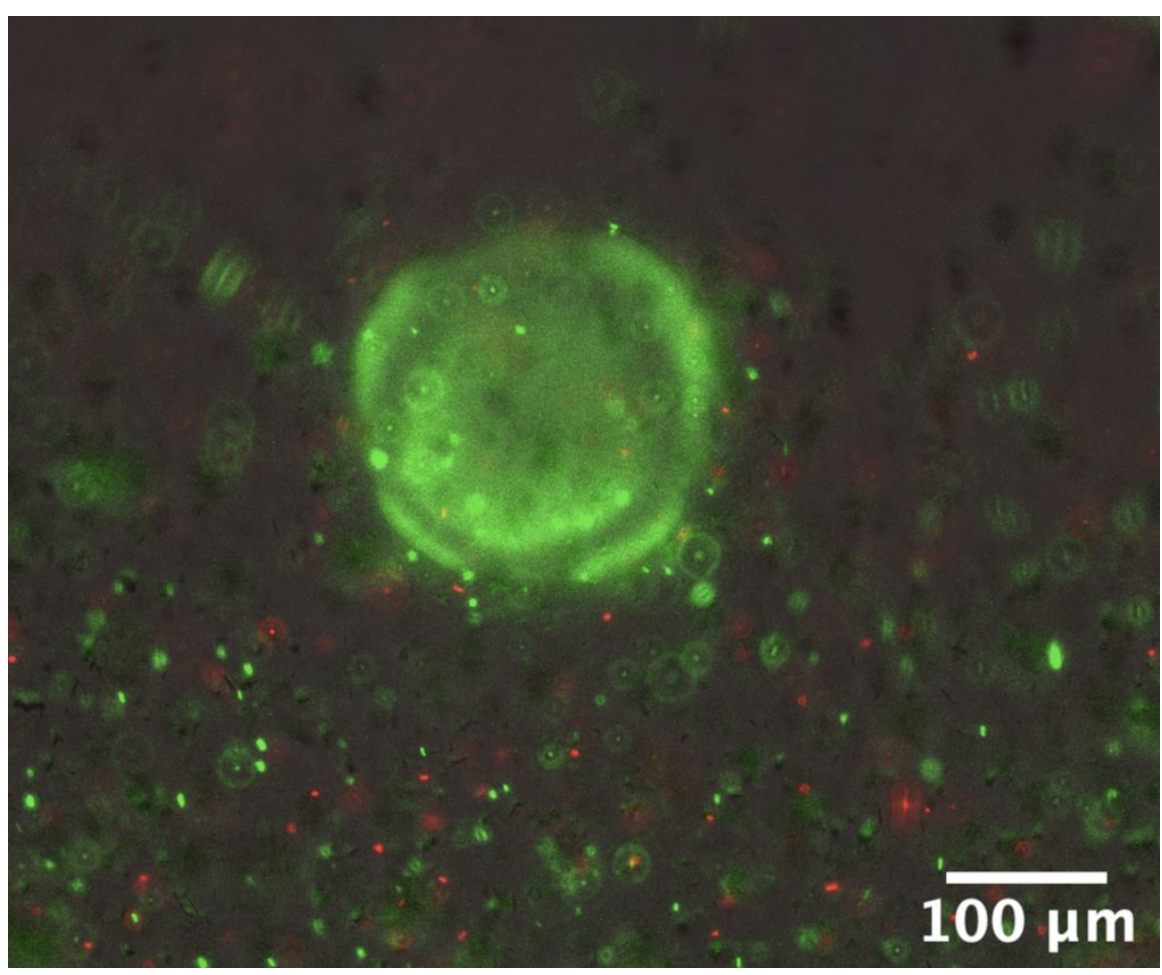

Figure S10 Crosslinked area of the hydrogel on a Petri dish surface covered with a mixture of 5\% GelMA, 5\% LAP, red- and green-fluorescent E. coli, obtained by exposure to $385 \mathrm{~nm}$ light for $45 \mathrm{~s}$, using a 100X objective with dual pinhole. 
Supplementary Table 2. Comparison between different materials commonly used for fabricating HiH MDAs.

\begin{tabular}{|c|c|c|c|c|}
\hline & FluorAcryl & FTDS $^{1}$ & CYTOP $^{2-4}$ & Teflon-AF ${ }^{5}$ \\
\hline MDA & Yes & Yes & Yes & Yes \\
\hline Well structures & Yes & No & Yes & Yes \\
\hline Water in air interface & Yes & Yes & Not tested & Not tested \\
\hline Price & $50 \$ / 100 \mathrm{~mL}$ & $\mathrm{~N} / \mathrm{A}$ & $3000 \$ / 100 \mathrm{~g}$ & $1500 \$ / 100 \mathrm{~mL}$ \\
\hline Resolution & $1 \mu \mathrm{m}$ & $1 \mu \mathrm{m}$ & $1 \mu \mathrm{m}$ & $1 \mu \mathrm{m}$ \\
\hline Layer thickness & $\begin{array}{c}300 \mathrm{~nm}-1 \mu \mathrm{m} \\
\text { (Thicker layers possibly } \\
\text { achievable, but not } \\
\text { tested yet) }\end{array}$ & Molecular monolayer & $\begin{array}{c}17 \mathrm{~nm}-1 \mu \mathrm{m} \\
\text { (Thicker layers can be } \\
\text { obtained by multiple spin } \\
\text { coating steps) }\end{array}$ & $3 \mu \mathrm{m}$ \\
\hline Autofluorescence & Low & Low & Low & Low \\
\hline Transparent & Yes & Yes & Yes & Yes \\
\hline Processing & $\begin{array}{l}\text { 1. Spin coating of FA } \\
\text { 2. Photopatterning } \\
\text { 3. Plasma etching } \\
\text { 4. } \mathrm{SF}_{6} \text { treatment }\end{array}$ & $\begin{array}{l}\text { 1. Spin coating of a } \\
\text { photoresist } \\
\text { 2. Photopatterning } \\
\text { 3. Molecular vapor } \\
\text { deposition of FDTS } \\
\text { 4. Lift-off of the } \\
\text { crosslinked } \\
\text { photoresist }\end{array}$ & $\begin{array}{l}\text { 1. Spin coating of CYTOP } \\
\text { 2. Spin coating of a } \\
\text { high viscosity } \\
\text { photoresist } \\
\text { 3. Photopatterning } \\
\text { 4. Reactive lon etching }\end{array}$ & $\begin{array}{l}\text { 1. Fluoroalkylsilane-based } \\
\text { priming of the glass wafer } \\
\text { 2. Spin coating of Teflon-AF } \\
\text { 3. Deposition of Parylene-C } \\
\text { to preserve the } \\
\text { hydrophobicity of Teflon-AF } \\
\text { during photopatterning } \\
\text { 4. Application of an aluminium } \\
\text { hard mask, photopatterned } \\
\text { and then etched through wet } \\
\text { chemistry. } \\
\text { 5. Oxygen plasma etching } \\
\text { 6. Removal of Parylene-C and } \\
\text { aluminium hard mask }\end{array}$ \\
\hline Other & & & $\begin{array}{l}\text { Requires an export } \\
\text { licence }\end{array}$ & \\
\hline
\end{tabular}


(1) Kunding, A. H.; Busk, L. L.; Webb, H.; Klafki, H. W.; Otto, M.; Kutter, J. P.; Dufva, M. Micro-Droplet Arrays for Micro-Compartmentalization Using an Air/Water Interface. Lab Chip 2018, 18(18), 2797-2805. https://doi.org/10.1039/c81c00608c.

(2) Sakakihara, S.; Araki, S.; Iino, R.; Noji, H. A Single-Molecule Enzymatic Assay in a Directly Accessible Femtoliter Droplet Array. Lab Chip 2010, 10 (24), 3355-3362. https://doi.org/10.1039/c0lc00062k.

(3) Iino, R.; Hayama, K.; Amezawa, H.; Sakakihara, S.; Kim, S. H.; Matsumono, Y.; Nishino, K.; Yamaguchi, A.; Noji, H. A Single-Cell Drug Efflux Assay in Bacteria by Using a Directly Accessible Femtoliter Droplet Array. Lab Chip 2012, 12 (20), 3923-3929. https://doi.org/10.1039/c2lc40394c.

(4) Kim, S. H.; Iwai, S.; Araki, S.; Sakakihara, S.; Iino, R.; Noji, H. Large-Scale Femtoliter Droplet Array for Digital Counting of Single Biomolecules. Lab Chip 2012, 12(23), 49864991. https://doi.org/10.1039/c2lc40632b.

(5) Leirs, K.; Tewari Kumar, P.; Decrop, D.; Pérez-Ruiz, E.; Leblebici, P.; Van Kelst, B.; Compernolle, G.; Meeuws, H.; Van Wesenbeeck, L.; Lagatie, O.; Stuyver, L.; Gils, A.; Lammertyn, J.; Spasic, D. Bioassay Development for Ultrasensitive Detection of Influenza A Nucleoprotein Using Digital ELISA. Anal. Chem. 2016, 88 (17), 8450-8458. https://doi.org/10.1021/acs.analchem.6b00502. 